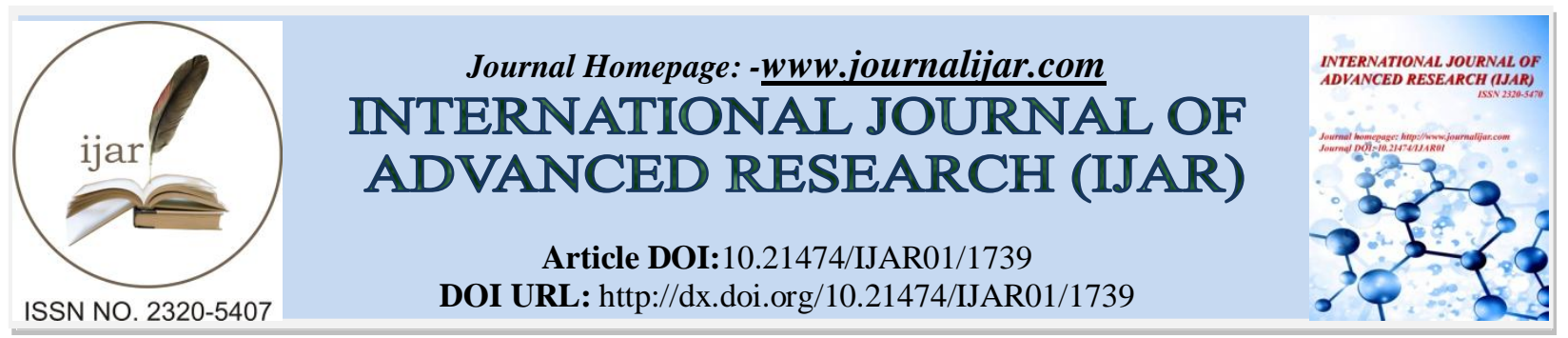

\title{
RESEARCH \\ AN ASSESSMENT OF WOMEN LEVEL OF ASSERTION OF REPRODUCTIVE HEALTH RIGHTS IN NSUKKA LGA OF ENUGU STATE, NIGERIA
}

\section{Loretta Chika Ukwuaba.}

Department of Adult and continuing Education, Enugu State University of Science and Technology, Enugu Nigeria

\section{Manuscript Info}

Manuscript History

Received: 12 July 2016

Final Accepted: 26 August 2016

Published: September 2016

Key words:-

Assessment, Reproductive health,

Assertion and Rights.
Abstract

The study determined the level of women's assertion of their reproductive rights in Enugu State. One research question and one hypothesis guided the study. A survey research design was used for the study. 172 were women randomly sample from 858 women registered in 28 women's community based organization in Nsukka Local Government Area of Enugu State. A structured questionnaire was used for data collection. The research question was answered using mean and grand mean while the hypothesis was tested using ttest statistic. A mean of 2.50and above was accepted while acalculated $\mathrm{t}$ above 1.96 was not accepted The results indicate that women assert their reproductive rights to a high level. There is a significant difference in the response of literate and non-literate on the level of assertion of their reproductive rights. It was recommended among other things that government should provide adequate funds for reproductive health programmes, awareness should be created for men on their reproductive health responsibilities to women.

Copy Right, IJAR, 2016,. All rights reserved.

\section{Introduction:-}

Women's reproductive health has been an issue of concern since the past decade. The International Conference on Population and Development (ICPD) held in Cairo, Egypt in 1994 made a remarkable shift from the population programme to the need to meet the reproductive health needs of the individual and couple as a key approach to improving quality of life of people and stabilizing the worlds' population.

1. Reproductive health components as outlined by Federal Ministry of Health

2. Safemotherhood comprising of prenatal care, safe delivery, essential obstetrics care, neo-natal care and breast feeding.

3. Family planning information and services.

4. Prevention and management of infertility and sexual dysfunctions of both men and women.

5. Prevention and management of complications of abortions.

6. Provision of safe abortion services where the law permits

7. Prevention and management of reproductive tract infection especially sexually transmitted diseases (STIS) including HIV/AIDS.

8. Promotion of healthy sexual maturation as from preadolescence, responsive and safe sexual maturation from adolescence, responsive and safe sex throughout the eyetime and gender equity.

9. Elimination of harmful practices such as female genital mutilation (FGM), premature marriage and domestic and sexual violence against women (Federal Ministry of Health, 2001). This implies that reproductive health 
has shifted from maternal and child healthand family planning to embrace a broader and more comprehensive way to addressing health related issues.

Reproductive health right is a human right yet it has not been given substantiveattention in most developing nations. Academic discourse on reproductive health rights is a relatively new phenomenon in Nigeria. However, a number of studies have emphasized the need for women to informed especially with regards to their health related issues. Momodu (2002) investigated the information needs and information seeking behaviour of rural dwellers in Ekpoma, Edo State. He identified that women particularly needed information on pre and postnatal care and current immunization facilities for their children and themselves. Like Momodu, Saleh and Lasisi (2011) examined the information needs and information seeking behaviour of rural women in Borno state, Nigeria. This study revealed that the most paramount health information required is ante natal and post natal care, immunizations especially on the six childhood killer diseases, how to prevent and manage Vesisco Virginal Fistula (VVF), and for safe delivery.

In another similar study, Nwagwu \& Ajama (2011) focused on the health information needs and information sources of women in rural oil palm business. Other studies include, the information needs and information seeking behaviour of other groups of people such as secondary school girls (Arowojolu \& Adekunle, 2000), patients with STD (Akinawo \& Oguntimehin, (1997) and family physicians (Shabi, Kuteyi, Odewale and Shabi, 2008).

Elsewhere in Africa, Rutakumwa \& Krogman (2000) carried out a study on the information needs and seeking behaviour of women in Uganda. The findings revealed that the primary concern of women in Uganda was for information on reproductive health especially with regard to information on the various ailments which can occur during pregnancy to both mother and child. They were also concerned about post natal care and birth control. These studies highlight the fact that women needs information for them to assert their health rights generally and reproductive health rights in particular.

The term reproductive right was coined in 1984 during the international meeting on women and health in Amsterdan. This event was seen as a starting point of the struggle to expand the scope of human right to reproductive health rights.

Reproductive rights consist of a number of separate human rights that are already recognized in national laws, international and international human right law document and other consensus document (Gbadamosi, 2012). The consensus document include the basic rights of all couples and individuals to freely and responsibly determine the number and spacing of their children and to have the information, education and the means to do so, the right to make decision concerning reproduction free from discrimination, coercion and violence (United Nations Population Funds, 1994).

Nigeria as one of the countries that approved the ICPD programme of action committed herself to the implication of the reproductive health concepts and achievement of the ICPD target in the interest of the health and development of her citizenry many policies were put in place in Nigeria to achieve the goals of ICPD.

The National Policy for Population and Development (NPPD) 1988 was adopted to address the pattern of population growth rate and its adverse effect on national development. The emergence of issues such as HIV/AIDs, poverty, gender inequality among others necessitated a review of the 1988 National Population Policy giving way to the National Policy for sustainable development of 2005. One of the goals of this policy is to improve the reproductive health of all Nigerians at every stage of the lifecycle.

However, in as much as policies were put in place to achieve good reproductive health for her citizens, poor reproductive health conditions are the leading cause of deaths and illnesses in women of child bearing age in Nigeria (United Nation's Population Funds, 2005). Reproductive rights until very recently were considered by most Africans as issues for discussion only by queers and liberal feminist group. Reproductive and sexual practices are viewed in the typical Africa traditional values and societal norms as very private issues not meant for public discussion (Aniekwu, 2006). Women's demand for sexual rights, safe abortion and reproductive choice are regarded as sacrilege. Cultural practices like female genital mutilation (FGM) in so many societies are not considered harmful or illegal.

The rights of Nigerian women to reproductive health and autonomy in all decisions relating to rights are frequently violated. Nigerian women like their counterparts in other parts of Africa are in every context socially, culturally, 
economically and politically victims of politics of exclusion which oppresses women to the advantage of men. Men readily entrench cultural, social, religious prejudice to marginalize, discriminate and disempowered women (Gbadamosi, 2012). Women in the Nigeria culture are not permitted to make input regarding child spacing or the number of children to have even when it endangers a woman's right to her life (Ifemeje, Obidinma and Umejiaku, 2012). These forces impede women's enjoyment of their traditional health rights.

In Nigeria, women are socialized into a culture of subordination due to the patriarchal nature of the Nigerian state. Patriarchy is a social stratification and differentiation on the basis of sex which provide paternal advantage to males while simultaneously placing severe constraints on the roles and activities of the females. Patriarchy gives men control over female sexuality.

The bane of patriarchy is more stringent among non-literate women or even some literate women and rural women whose views subscribe to the traditional views of women and marriage. These women will follow the dictate of their husbands and inlaws even to the detriments of their health (Anina in Ige, 2012). The average Nigerian rural woman has little or no economic power and this situation makes her totally under the authority of her husband and his family who takes decisions regarding reproductive health for her. Their ability to access reproductive health services depend on the views of her family members (National Populations Commission (NPC), 2008). Gender in equality militate against the health of women and girls especially in the areas of nutrition, education and reproductive health.

Increased empowerment of women through education is likely to increase their ability to negotiate reproductive rights decisions, seek out and use health services to better meet their reproductive goals like safe motherhood, use of contraceptives, child-spacing number of children among others (NPCS, 2008). An educated woman is generally more likely to have better knowledge about health care practices (Ukwuaba and Igbo, 2015). It therefore means that a non-literate woman may not have access to healthcare because of lack of knowledge unless a relative or health provider takes the pain in seeing to it that she access health facilities close to her.

The 2008 National Demographic Health Survey (NDHS) indicate that $60 \%$ of non-literate women had no antenatal care, $70.4 \%$ had no tetanus toxoid during pregnancy, $89 \%$ delivered at home, $74 \%$ hot no postnatal check-ups, while literate women with education higher than secondary school had only $1.7 \%$ not attending antenatal care, $4.6 \%$ did not take tetanus toxoid etc. (NPCS, 2008). This implies that a woman level of education determines her knowledge and access to reproductive health and rights.

In Enugu State awareness on women's reproductive health and rights has been created through government agencies and non-governmental including faith-based organizations,such as ministries of health, education and women affairs, Women for Women International (WFWI), Development Education Centre, Partnership for Transforming Health Services (PATHS), Women's Aids Collectives etc. The awareness was achieved through public enlightenment, workshop, seminars, training, participatory learning, radio jingles etc. This study therefore seeks to determine the level of women's assertion of their reproductive health rights in Nsukka Local Government Area of Enugu State, Nigeria.

\section{Research Question}

What is the level of women's assertion of reproductive health rights in Nsukka Local Government Area of Enugu State?

\section{Null Hypothesis}

There is no significant difference between the mean scores of literate and non-literate women response in Nsukka Local Government of Enugu State on their level of assertion of reproductive health right.

\section{Research Method}

The design of the study is a survey research design. Eight hundred and fifty eight (858) women who are members of 28 registered women community based organization formed the population for the study. One hundred and seventy two (172) was sampled from the population which is $20 \%$ of the total population. The instrument for data collection was a 14-itemed questionnaire with response options of Very High Level (VHL), High Level (HL), Low Level (LL) and Very Low Level (VLL). This instrument was used as interview schedule for non-literate participants in the survey. 
The research question was answered using mean scores and hypothesis (Ho) tested with t-test at 0.05 level of significance and a degree of freedom of 1.96.

A mean of 2.50 implies that the respondents comply to a higher level to reproductive health rights and below 2.50 is otherwise, consequently. When the calculated t-test is less than 1.96 it implies acceptance of the $\mathrm{H}_{0}$, while above 1.96 connotes non-acceptance.

\section{Results:-}

The result of the data analysis were presented in table according to research question and hypothesis.

\section{Research Question:-}

What is the level of women's assertion of reproductive health rights in Nsukka Local Government Area of Enugu State?

Table 1:-Mean score on the level of women's assertion of their reproductive health rights

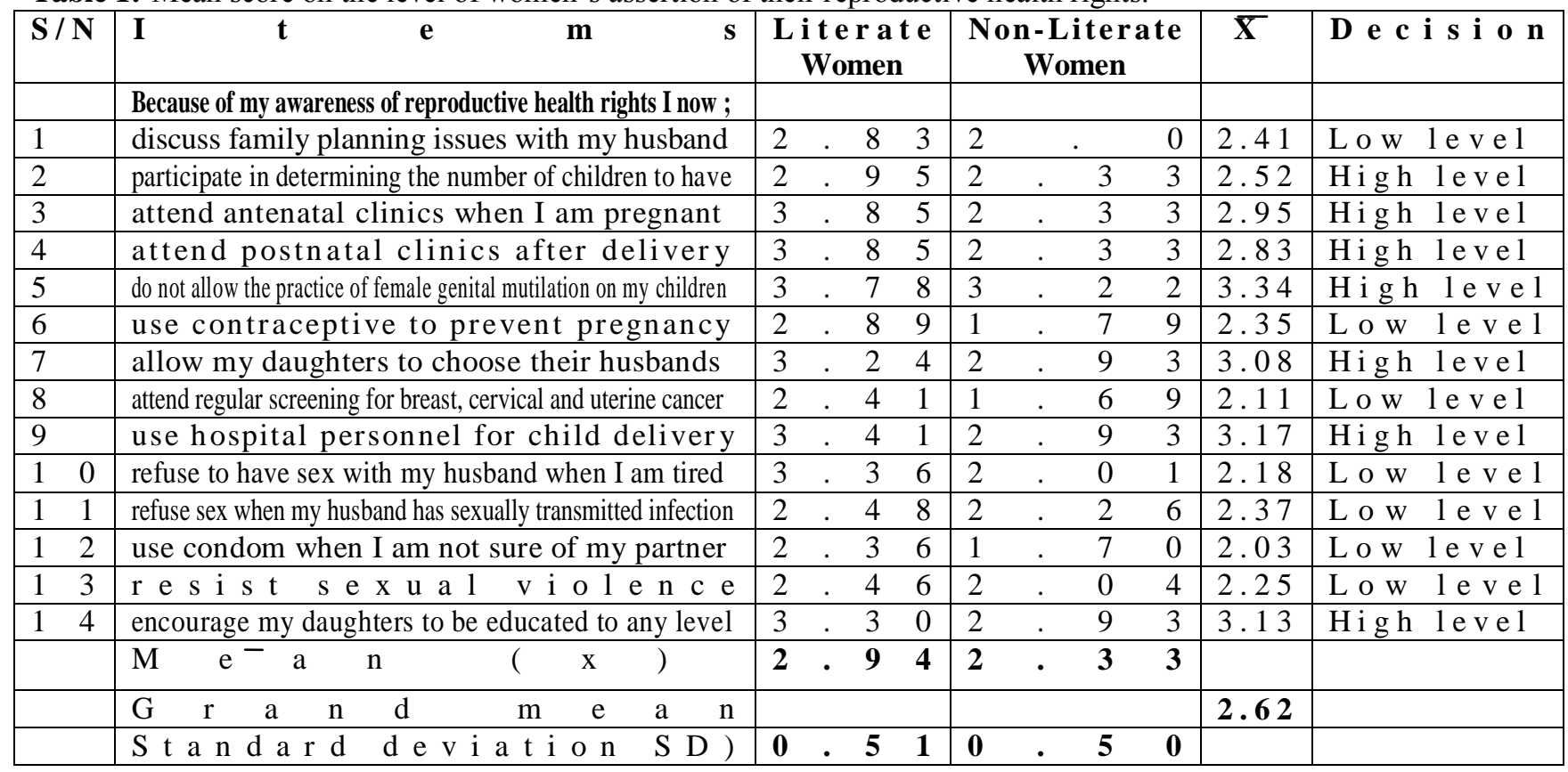

The table shows that a grand mean of 2.62 was obtained for all the 14 items indicating that women in Nsukka local government area of Enugu State respond to a high level to reproductive health rights.

\section{Testing of Hypothesis:-}

There is no significant difference between the mean scores of literate and non-literate women on their level of assertion to reproductive health rights in Nsukka Local Government Area.

Table II: t-test of difference between the mean scores of literate and non-literate women on their level of assertion to reproductive health rights in Nsukka Local Government Area.

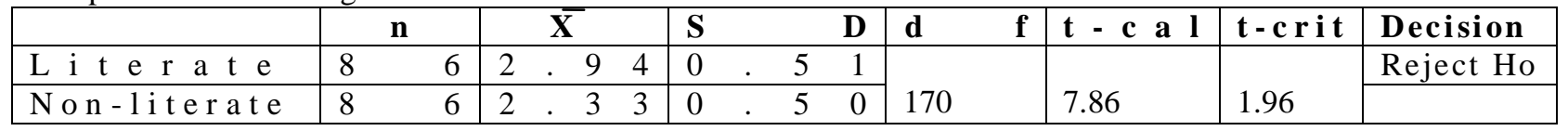

Table 2 indicate that the calculated t-value at .05 level of significance and 170 degree of freedom is 7.86 while the critical t-value is 1.96. Since the calculated value of $t$ is greater than the critical value of $t$, the null hypothesis is therefore rejected. This implies that a significant difference exist between the mean scores of literate and nonliterate women on their level of response to reproductive health rights. 


\section{Discussion of Findings:-}

Results from data analysis revealed that women in Nsukka local government assert their reproductive health rights to a high level. Women assert positivelyto rights such as participating in determining the number of children to have; attending antenatal and post-natal clinics, do not practice female genital mutilation (FGM), use of hospital personnel for child delivery among others. On the other hand, reproductive rights such as discussing family planning issues; use of contraceptives, regular screening for cancer, refusal of sexual intercourse when tired or unsafe; use of condom and resisting sexual violence was to a low level. This is in line with the earlier findings of NPC (2008) and Ifemeje, Obidinma and Umejiaku (2012) that women follow the dictate of their husbands and inlaws in reproductive matters even to the deteriments of their own health, due to ignorance, poverty and patriarchy. This implies that in as much as women assert some reproductive health rights, factors such as patriarchy, ignorance, illiteracy poverty and environment must have impeded women's total assertion of these rights.

The null hypothesis indicate that significant difference exist between the responses of literate and non-literate women on the level they assertion their reproductive health rights. Literate women responded positively to eleven (11) out of the fourteen (14) items. This is in line with the earlier findings of NPC (2008) that education increases women's ability to reproductive right decisions, seek out and use health services to meet their reproductive goals like safe motherhood, child spacing, use of contraceptive among others

Most illiterate women do not use health services. This according to Ukwuaba and Igbo (2015) is as a result of lack of knowledge about healthful living practice and how to access health services. Most of these illiterate women depend solely on their husbands and relatives to take reproductive health decisions for them due to ignorance. These decisions may be affected by patriarchy which invariably will not favour women. An educated woman will have knowledge of good health practices. This findings implies that education exposes women to knowledge and access to reproductive health rights.

\section{Conclusion:-}

The finding indicate that women in Nsukka local government area of Enugu State assert their reproductive right to a high level. However, the mean rating of literate and non-literate women studied differed significantly. This shows that in as much women assert their reproductive rights in local government area of the State, the rate of assertion is very low among non-literate women. The findings from this study invariably indicate that education will enhance women's knowledge of reproductive health issue and assertion of their reproductive rights.

\section{Recommendations:-}

Based on the findings of the study, the following recommendations were made.

1. Government should domesticate international conventions on women's rights.

2. Right-based reproductive health policies like free antenatal and post-natal care and family planning service should be developed.

3. Creating awareness for men on their reproductive health responsibilities to women.

4. Empowerment of women through education

5. Provision of adequate funds for reproductive health programmes in rural communities

6. Provision of functional adult education programme in all the communities in the state.

\section{References:-}

1. Aniekwu, N. (2006). Gender and reproductive health: Towards advancing judiciary reforms in Nigerian Law.

2. www.nials-nigeria.org/Journals/Nkoli-Advancing\%20Judicial\%20Reform-Reproductive\%20Rights.pdf. Accessed 2/8/15.

3. Gbadamosi, O. (2012). Reproductive health and rights.

4. www.justice.democracy.org/abstract.pdf. Accessed 19/6/15

5. Federal Ministry of Health (FMOH) (2001). Nigerian National Health Policy and Strategy to achieve Quality Reproductive and Sexual Health for all Nigerians. 12. Abuja: Author.

6. Ifemeje, S.; Obidinma, E. \& Umejiaku, N. (2013). A critic of incessant violation of women's health and reproductive rights in Nigeria. Journal of law, policy and globalization, 11, 2013. www.iiste.org/journal/index.php/JLPG/article/viewfile/487314951. Accessed 19/6/15. 
7. Ige, A. (2012). Women and the right to health in Nigeria: The intersections. British Journal of Arts and social sciences 5(2) 177-185://www.bjournal.uk/BJAss.aspx. Accessed 17/6/2015.

8. Momodu, M. O. (2002). Information needs and information seeking behaviour of rural Dwellers in Nigeria: a case study of Ekpoma in Esan West Local Government ofEdo State, Nigeria. Library Review 51 (8): 406-410.

9. National Population Commission (NPC) (2008). Nigeria demographic health survey, Abuja: Author.

10. Nwagwu, W. E. \& Ajama, M. (2011). Women's health information needs and information Sources: a study of a rural oil palm business community in South-Western Nigeria. Annals of Library and Information Studies. 270281.

11. Saleh, A. G. \& Lasisi, F.I., (2011). Information needs and information seeking behavior of rural women in Borno State, Nigeria. Library Philosophy and Practice (e-journal) Paper 625. Available http://digitalcommons.unl.edu/libphilprac/625

12. United Nations Population Funds (UNFRA) (1994). Report of International Conference on Population and development (ICPD) Cairo. Available at http://www.refworld.org/docid/4a54bc080.html. accessed 9/8/15.

13. United Nations Population Funds (UNFPA) (2005). The State of the world population 2005.The promise of equity, gender equality, reproductive health and millennium development goals, New York: Author.

14. Ukwuaba, L.C. and Igbo, R.O. (2015). Encouraging good health practices among rural women in Nigeria through non-formal education. Journal of Nigerian National Council for Adult Education NNCAE 20(1) 152159. 